\title{
3 Climate change risks to push one-third of global food 4 production outside Safe Climatic Space
}

5 Matti Kummu ${ }^{1 \# *}$, Matias Heino ${ }^{1 \#}$, Maija Taka ${ }^{1}$, Olli Varis ${ }^{1}$, Daniel Viviroli ${ }^{2}$

6 1. Water and Development Research Group, Aalto University, Espoo, Finland

7 2. Department of Geography, University of Zürich, Switzerland

8 \# contributed equally to the manuscript

$9 *$ corresponding author (matti.kummu@aalto.fi)

10 Climate change will alter key climatic conditions which human societies directly rely on and

11 which, for example, food production is adjusted to. Here, using Holdridge Life Zones, we define

12 Safe Climatic Space (SCS), a concept that incorporates the decisive climatic characteristics of

13 precipitation, temperature and aridity. This allows us first to define the climatic niche of

14 current food production and then estimate critical areas where food production will face an

15 elevated risk of being pushed outside the SCS by climate change. We show that a rapid and

16 unhalted growth of GHG emissions (SSP5-8.5) could force $31 \%\left(25-37 \%\right.$ with $5^{\text {th }}-95^{\text {th }}$ percentile

17 confidence interval) of global food crop production and $34 \%$ (26-43\%) of livestock production

18 beyond the SCS by 2081-2100. Our results underpin the importance of committing to a low

19 emission scenario (SSP1-2.6), whereupon the extent of food production facing unprecedented

20 conditions would be a fraction. The most vulnerable areas are the ones at risk of leaving SCS

21 with low resilience to cope with the change, particularly South and Southeast Asia and Africa's

22 Sudano-Sahelian Zone.

Keywords: crop production; livestock production; Safe Operating Space; climatic conditions; climate 
27 Ecosystems and human societies have adapted to relatively stable Holocene climate conditions over the past millennia ${ }^{1,2}$. The majority of food production is based on agricultural practices developed for these conditions ${ }^{2,3}$. There are already signs that the recent, accelerating global environmental change is impacting many important crops throughout the planet ${ }^{4,5}$. Often the change is manifested in several indicators. This also applies to climate change, projected to change temperature and rainfall patterns, as well as aridity arising from those ${ }^{6}$. These key parameters directly affect societies and their lifesustaining activities such as food production ${ }^{7,8}$ and water availability . $^{9}$

Various studies have assessed the changes in agricultural conditions under climate change ${ }^{10-12}$ by analysing the changes in climatic conditions $\mathrm{s}^{12-14}$ and their potential impact on yields ${ }^{11,15,16}$. It would, however, be important to also understand which areas might experience truly novel climate under which no major agriculture exists today, along the lines of Safe Operating Space (SOS) and climate niche concepts for human societies ${ }^{17}$. SOS refers by its definition ${ }^{2}$ to the Earth system conditions that would sustain human life as we know it. Although the Planetary Boundary framework includes an SOS for climate change ${ }^{18}$, it is defined through global atmospheric carbon dioxide concentration and does not specify climatic thresholds that could be applied on a local scale. Xu et al ${ }^{17}$, in turn, argue that it is necessary to "understand climatic conditions for human thriving", as it might be difficult to adapt to new climatic conditions with the pace projected by climate change. They find that a considerable part of the population will fall outside the temperature niche due to climate change. In this study we aim to go beyond the existing studies by first defining the novel concept Safe Climatic Space (SCS) by using a combination of three climatic parameters. SCS is defined here as the climate conditions to which current food production systems (here crop production and livestock production separately) are accustomed to (Methods; Supplementary Fig. 3), an analogue to SOS concepts such as Planetary Boundaries ${ }^{2,18}$ and climatic niche ${ }^{17}$. For the SCS, we propose to use a combination of the selected key climatic factors in an integrated way instead of assessing a single indicator at the time. Therefore, we use the Holdridge Life Zone (HLZ) concept ${ }^{19,20}$ to map the SCS, and to identify which food production areas would stay within it under climate change conditions. The HLZ divides Earth into 38 zones based on three climatic factors: annual precipitation, biotemperature and aridity (Fig. 1; Methods). It also considers whether an area experiences frost or not ${ }^{19}$. All these factors are important for both livestock ${ }^{17,21,22}$ and crop production ${ }^{23}$. Previously, the HLZ concept has been successfully used for biomass estimations ${ }^{24}$, as well as for analysing climate-soil ${ }^{25}$ and climatevegetation ${ }^{26}$ relationships, among other fields.

Further, unlike for example the Köppen-Geiger climate classification ${ }^{27}$, the Holdridge concept is not limited to map the categorical changes but also allows to assess the magnitude and direction of changes (Methods; Supplementary Fig. 6). Therefore, the concept allows us to map how the above- 
61 mentioned climatic factors together would change in an integrated manner and thus map the areas

62 where climate change introduces a risk to push the food production areas outside this safe space.

63 In addition to applying the HLZ to define the SCS and potential risk of areas to slide out of it, we also

64 analyse the changes in HLZ zones. Although studies mapping HLZs under future climate exist, these

65 are conducted either on regional scale ${ }^{28,29}$ or with simplistic climate scenarios (double $\mathrm{CO}_{2}$

66 emission $)^{30}$. Thus, our mapping reveals important insights on the changes in HLZs too.

67 Our suggested SCS framework using Holdridge zoning provides thus a novel concept to define the

68 climatic niche for current food production and allows us to holistically study the multifaceted and

69 spatially heterogeneous risks of climate change on it. To assess these risks, we link the climate change

70 induced alterations on HLZs over the coming 80 years with spatial gridded global datasets of 1)

71 current production of 27 major food crops $^{31}$ (Methods) and 2) current livestock production of seven

72 major livestock types ${ }^{32}$ as well as 3 ) the resilience of human societies to cope with these changes ${ }^{33}$.

73 We use the data for the current situation (year 2010), and thus, we are able to identify current food

74 production areas in which an elevated risk for exiting the SCS coincides with low capacity of the

75 society to cope with additional stresses. 

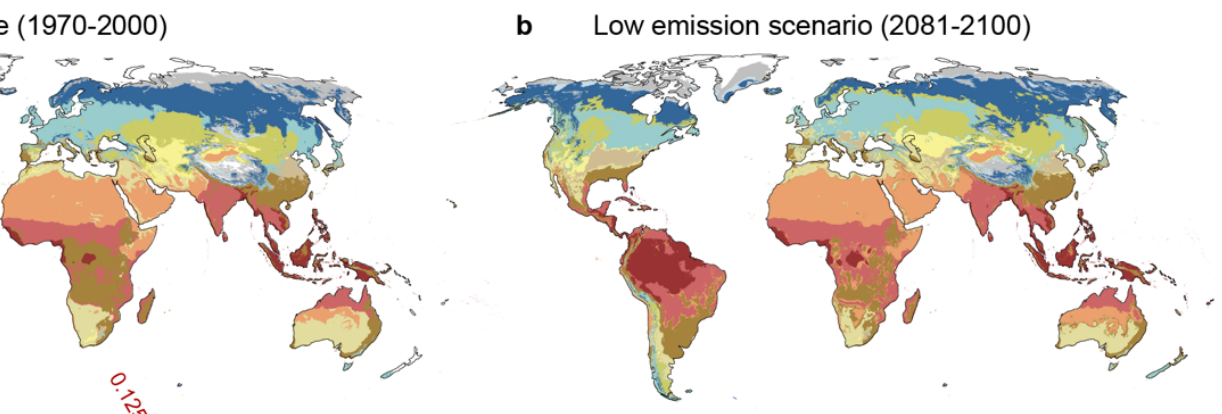

d

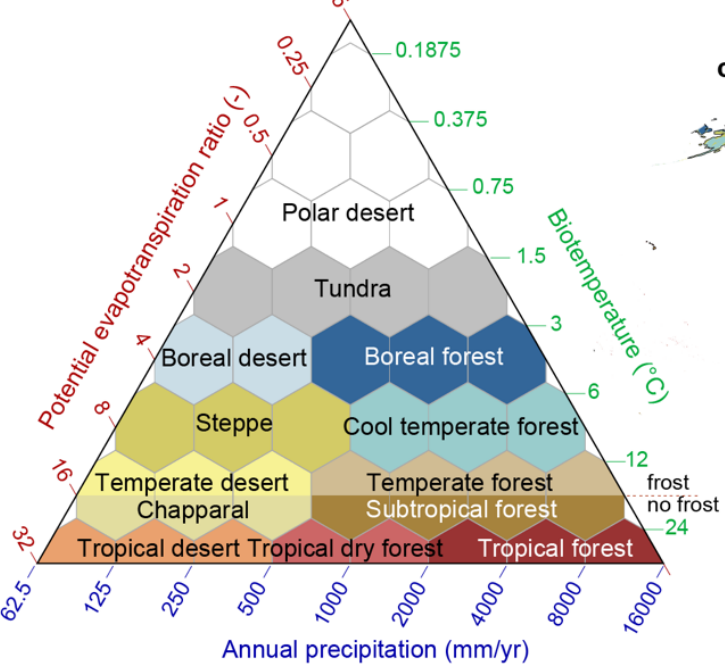

c High emission scenario (2081-2100)

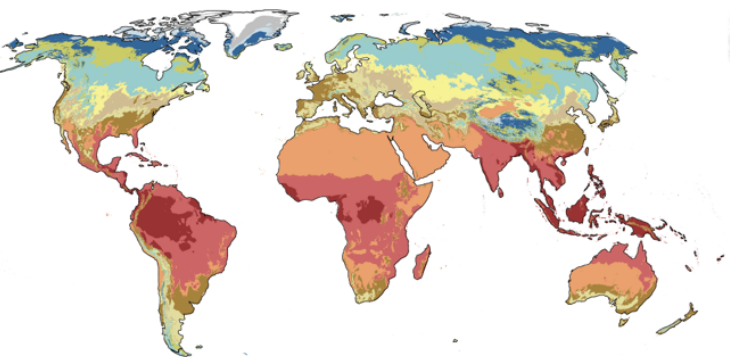

Figure 1. Holdridge Life Zones (HLZ) for baseline period (1970-2000) (a) as well as two climate change scenarios for 2081-2100 (b-c). Low emission scenario refers to SSP1-2.6 scenario while high emissions scenario to SSP5-8.5 scenario under CMIP6 framework. The Holdridge triangle (d) shows the location of each $H L Z$ in relation to biotemperature, potential evapotranspiration (PET) ratio, and annual precipitation; here the original 38 zones were aggregated into 13 zones following Leemans ${ }^{30}$ (Methods). The maps in (a-c) illustrate the same colour classes as (d). Holdridge triangle (d) is modified from Halasz ${ }^{34}$. Note: Antarctica was part of the analysis but not shown in the maps. Data of Holdridge zones as for all the four assessed time periods (see Methods) are available under the link provided in the data availability statement.

\section{Results}

\section{Largest zonal changes in polar, mountain and Sahel areas}

We estimated the HLZs for baseline conditions (1970-2000) as well as for future conditions (20212040, 2041-2060, 2061-2080, and 2081-2100; note: most of the results are presented only for the last time step) under two climate change scenarios on both extremes (i.e., low emission scenario SSP1-2.6 and high emission scenario SSP5-8.5) under the most recent CMIP6 framework. We used spatially high-resolution ( 5 arc-min, or $\sim 10 \mathrm{~km}$ at the equator) data from 8 global circulation models, downscaled and bias corrected by WorldClim ${ }^{35}$ (Methods; Supplementary Fig. 1). We were thus able to map how the Holdridge Life Zones would spatially change over this century.

Among the largest changes by 2081-2100 in HLZs under the climate change scenarios assessed is the shrinking of the Boreal forest zone, from 18.0 million $\mathrm{km}^{2}\left(\mathrm{Mkm}^{2}\right)$ to $14.8 / 8.0$ (SSP1-2.6 and SSP58.5 , respectively) $\mathrm{Mkm}^{2}$. Largest positive net increase is the growing Tropical dry forest zone from 15.0 to $19.2 / 27.7 \mathrm{Mkm}^{2}$, ending up being globally the largest zone together with Tropical desert in 
future conditions (see Supplementary Table 1). The largest reduction in relative terms occurs in Tundra ( $-39 \% /-75 \%$; i.e., almost disappearing under SSP5-8.5 from 9.1 to less than $2.5 \mathrm{Mkm}^{2}$ ) and Boreal forest $(-20 \% /-57 \%)$. In contrast, the largest increase in relative terms would occur in Boreal desert $(+159 \% /+75 \%)$, Temperate desert $(+24 \% /+110 \%)$ and Temperate forest $(+48 \% /+118 \%)$

(Supplementary Table 1). Particularly alarming is the potential net increase of the combined area of 'desert zones' from 59.7 to $62.7 / 64.3 \mathrm{Mkm}^{2}$ (of total $150 \mathrm{Mkm}^{2}$ included in the analysis), indicating drier conditions in many regions.

As the Holdridge concept allows not only to assess changes in climate zones, but also the magnitude and direction of change (Methods; Supplementary Fig. 6), we were able to map these changes (Fig. 2, Supplementary Fig. 4) even in areas where the climate zone itself would remain unchanged in future conditions. To measure this change, we assessed for each grid cell the distance between the future location and baseline location within the HLZ triangle, as illustrated in Supplementary Fig. 6. The distance was normalised with the distance between two Holdridge Zone centroids, so that a change of 1 unit refers to a change that would be required to move from the centroid of one zone to another. The largest change in both future scenarios (SSP1-2.6 and SSP5-8.5) occurs in the polar region, Sahel as well as major mountain areas (Fig. 2). For both emission scenarios, the majority of the regions will develop towards more arid conditions, except for parts of Northern Africa and the Middle East where conditions would become wetter (Supplementary Fig. 4).
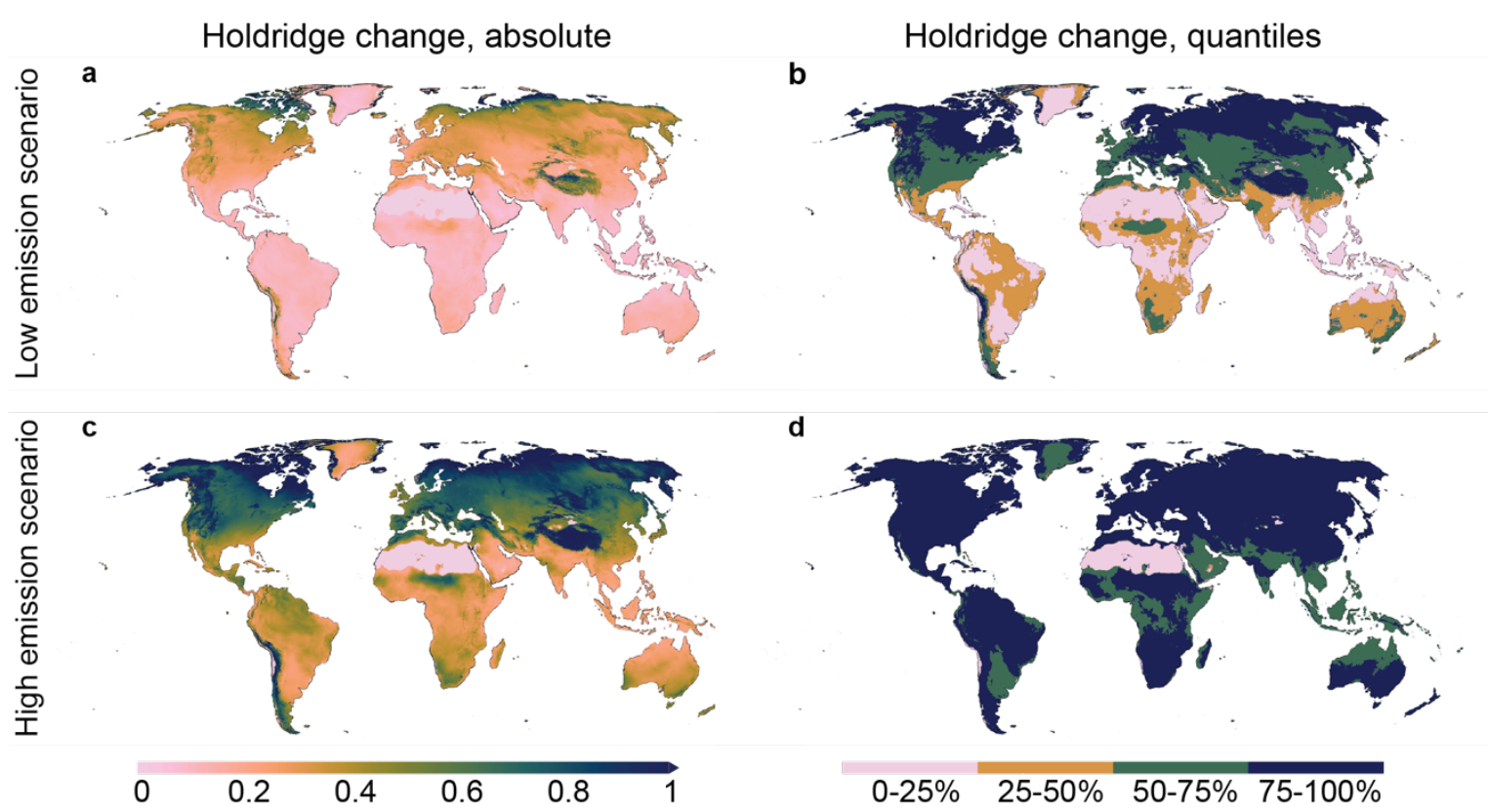

d

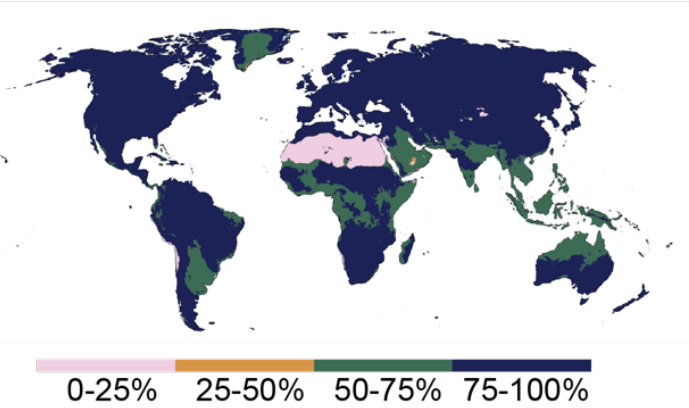

117 Figure 2. Absolute (left) and quantiles (right) of Holdridge zonal change under two climate change scenarios 118 for 2081-2100: low emission scenario - SSP1-2.6 ( $a, b)$ and high emission scenario - SSP5-8.5 (c, $d)$. The 119 absolute change is scaled so that value 1 refers to the distance between two Holdridge zone centroids (Fig. 1, 120 Supplementary Fig. 6; see also Methods), meaning a distance that is required to move from 'centre' of one zone to another. Note that quantile limits were derived relative to SSP1-2.6 for both climate change scenarios; i.e., we used the SSP1-2.6 results to map the change thresholds for quantiles and used these same thresholds for SSP5-8.5 so that scenarios would be comparable. See direction of change in Supplementary Fig. 4. 


\section{Low resilience combined with high HLZ change introduces high risk}

125 Societies have varying abilities to react to changes in climatic zones, depending on their resilience ${ }^{1}$ to 126 cope with the potential disruptions. Thus, we further linked the gridded global dataset of resilience ${ }^{33}$ 127 with 5 arc-min resolution ( $\sim 10 \mathrm{~km}$ at equator) for year 2010 (Methods) to the hotspot analysis to 128 identify the most vulnerable areas. The low resilience areas (bottom $25^{\text {th }}$ percentile) cover a large part 129 of South Asia, Middle East and Africa (Supplementary Fig. 5d).

130 When considering resilience with the HLZ change, the difference between the two scenarios is 131 remarkable. Under the low emission scenario (SSP1-2.6), the areas under most critical risk (i.e., 132 lowest $25^{\text {th }}$ percentile of resilience and top $25^{\text {th }}$ percentile of change in HLZ) lie in Sahel area and the 133 Middle East, covering around 1\% of global crop and livestock production (Fig. 3a). If nations are not 134 able to halt the growth in GHG emissions and the global community ends up following the path of the most extreme climate change scenario (SSP5-8.5), portions may rise as high as $32 \%$ for crop

136 production and 34\% for livestock (Fig. 3). These most critical areas would then cover most of the 137 Middle East, a large part of South Asia as well as parts of Sub-Saharan Africa and Central America 138 (Fig. 3b). Remarkably, over two thirds of crop production and over 70\% of global livestock 139 production would be under high and critical risk zones (combination of high change in HLZ and low 140 resilience or very high change in HLZ and high to moderate resilience, see Fig. 3).

141 As the results are sensitive to the choice of resilience percentile $\left(25^{\text {th }}\right.$ percentile $)$ chosen for low 142 resilience class, we tested this sensitivity by doing the analyses with $20^{\text {th }}$ to $30^{\text {th }}$ percentiles too. We 143 found that the crop and livestock production in the critical risk zone under high emission scenario 144 would vary between $28-36 \%$ and $30-39 \%$, respectively (Supplementary Table 6). The uncertainty 145 estimates in HLZs are presented in the following section. 
a

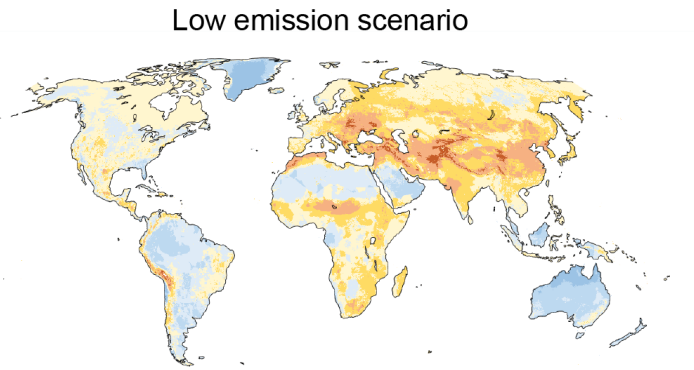

b High emission scenario

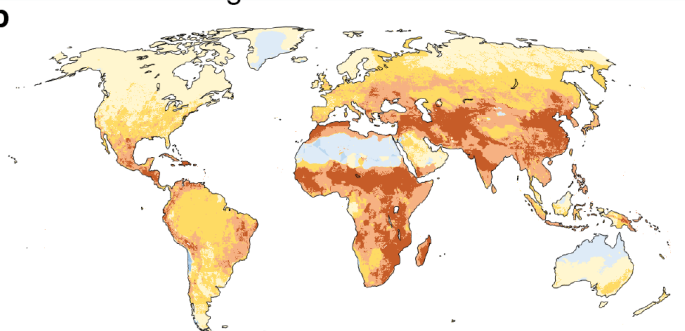

Food crop production (\%)

\begin{tabular}{|c|c|c|c|c|c|c|c|}
\hline 0 & 0.3 & 5.5 & 1.4 & 0 & 0 & 0 & 7.3 \\
\hline 1.2 & 1.6 & 13 & 2.1 & 0 & 0 & 1 & 17 \\
\hline 4.9 & 3.9 & 8.1 & 3.7 & 0 & 0 & 4.4 & 16 \\
\hline 17 & 17 & 19 & 0.6 & 0.5 & 0 & 21 & 32 \\
\hline
\end{tabular}

Livestock production (\%)

\begin{tabular}{|c|c|c|c|c|}
\hline \multirow{2}{*}{$\begin{array}{l}\text { very high } \\
\text { high }\end{array}$} & 0.2 & 0.9 & 3.3 & 1.1 \\
\hline & 2.5 & 5.3 & 7.8 & 2 \\
\hline \multirow{3}{*}{$\begin{array}{l}\text { moderate } \\
\text { low }\end{array}$} & 5.9 & 8.3 & 6.4 & 2.5 \\
\hline & 14 & 23 & 15 & 1.3 \\
\hline & low & $d e$ & high & very \\
\hline
\end{tabular}

\begin{tabular}{|c|c|c|c|c|}
\hline 0 & 0 & 0.3 & 5.2 & \\
\hline 0 & 0 & 1.9 & 16 & \\
\hline 0.2 & 0 & 4.4 & 18 & - High risk zone \\
\hline 0.3 & 0 & 19 & 34 & \\
\hline
\end{tabular}

147 Figure 3. Classified Holdridge change and resilience as well as their relation to livestock and food crop

148 production extent for low emission scenario - SSP1-2.6 (a) and high emission scenario - SSP5-8.5 (b) for 2081-

149 2100. The classes for Holdridge change and resilience are based on area-weighted quantiles; 0-25\% (low), 25-

$15050 \%$ (moderate), 50-75\% (high), 75-100\% (very high). High risk zone is defined as where resilience is moderate and Holdridge change very high, or resilience is low and Holdridge change is high or very high. Similar to Fig. 2, Holdridge change quantiles were always derived relative to the SSP1-2.6 scenario, i.e., we used the SSP1-2.6 results to map the change thresholds for quantiles and used these same thresholds for SSP5-8.5 so that scenarios would be comparable. See Supplementary Tables 2-5 for tabulated results and Supplementary Table 6 for sensitivity analysis of resilience percentile threshold.

\section{Large proportion of food production beyond SCS}

157 The estimated large changes in climate zones (Fig. 2) risks pushing remarkable parts of global food 158 production outside the SCS (i.e., Safe Climatic Space). We first defined the SCSs separately for crop production and livestock production by mapping the baseline climatic conditions in which $95 \%$ of

160 highest crop and livestock production areas are located (Methods, Supplementary Fig. 3). We then compared the future climatic conditions in every spatial location ( 5 arc-min grid) to these SCSs, separately for these two food production sectors, and were thus able to identify the areas in risk of falling outside the SCS (Fig. 4).

164 When comparing the SCS (i.e., climatic niche) for crop and livestock production areas (blue area in 165 Fig. 4; Supplementary Fig. 3), we can see that, as expected, the SCS is much larger for livestock. The SCS for livestock production spans over drier as well as wetter areas, when compared to the one for crop production, while the upper boundary for biotemperature is relatively similar to both (between $3^{\circ} \mathrm{C}$ and $6^{\circ} \mathrm{C}$ ) (Fig. 4). 
169 Our results show strong contrasts between the two examined climate scenarios. In the low emission 170 scenario (SSP1-2.6) only rather limited parts of current crop production $\left(8 \% ; 4-10 \%\right.$ with $5^{\text {th }}-95^{\text {th }}$ 171 percentile confidence interval; depending on how many global circulation models agree on the 172 change; see Supplementary Table 7) and livestock production (4\%; 2-8\%) would fall outside the SCS 173 (Fig. 4a-b; Fig. 5a). In the case of the high emission scenario (SSP5-8.5), globally as much as 31\% 174 (25-37\%) of the crop production and 34\% (26-43\%) of livestock production would be at risk for 175 facing conditions beyond the corresponding SCSs (Fig. 4c-d; Fig. 5b). When looking at the evolution 176 over time, we found that the two used emission scenarios resulted in a rather similar outcome for the 177 first two time steps (2021-2040, 2041-2060), after which there is strong divergence between them 178 (Fig 5).

179 Further, the risks for individual countries appear very heterogeneous: In 52 out of the 177 countries 180 a majority being European - the entire food production system would stay within the Safe Climatic 181 Space (Fig. 6; Supplementary data). This does not mean that those countries would not experience 182 changes in their climatic conditions (Fig. 1a-c) but the projected future climatic conditions are 183 presently experienced elsewhere in the world and are thus not novel globally. In the worst position 184 would be e.g., Benin, Cambodia, Ghana, Guinea-Bissau, Guyana, and Suriname where alarmingly 185 over $95 \%$ of both crop and livestock production would move beyond the SCS.

186 Unfortunately, in many of the high-impacted areas the resilience to cope with the change is currently 187 low (Fig. 6). Critical areas - facing both actual risk in falling outside SCS and already low in 188 resilience - can be extensively found in the Sahel region, the horn of Africa as well as in South and 189 Southeast Asia (Fig. 6). Particularly Benin and Cambodia (over 95\% of food production beyond the 190 SCS and under low resilience) as well as Burkina Faso, Chad, Côte d'Ivoire, Guinea-Bissau, Niger, 191 and Sierra Leone (over 85\%) would face severe challenges in producing their food if the world 192 community fails to combat climate change and follow the high-end SSP5-8.5 scenario and their 193 resilience remains low. Altogether, $20 \%$ of the world's current crop production and $18 \%$ of livestock 194 production are at risk for falling outside SCS with low resilience to cope with that change 195 (Supplementary data). 


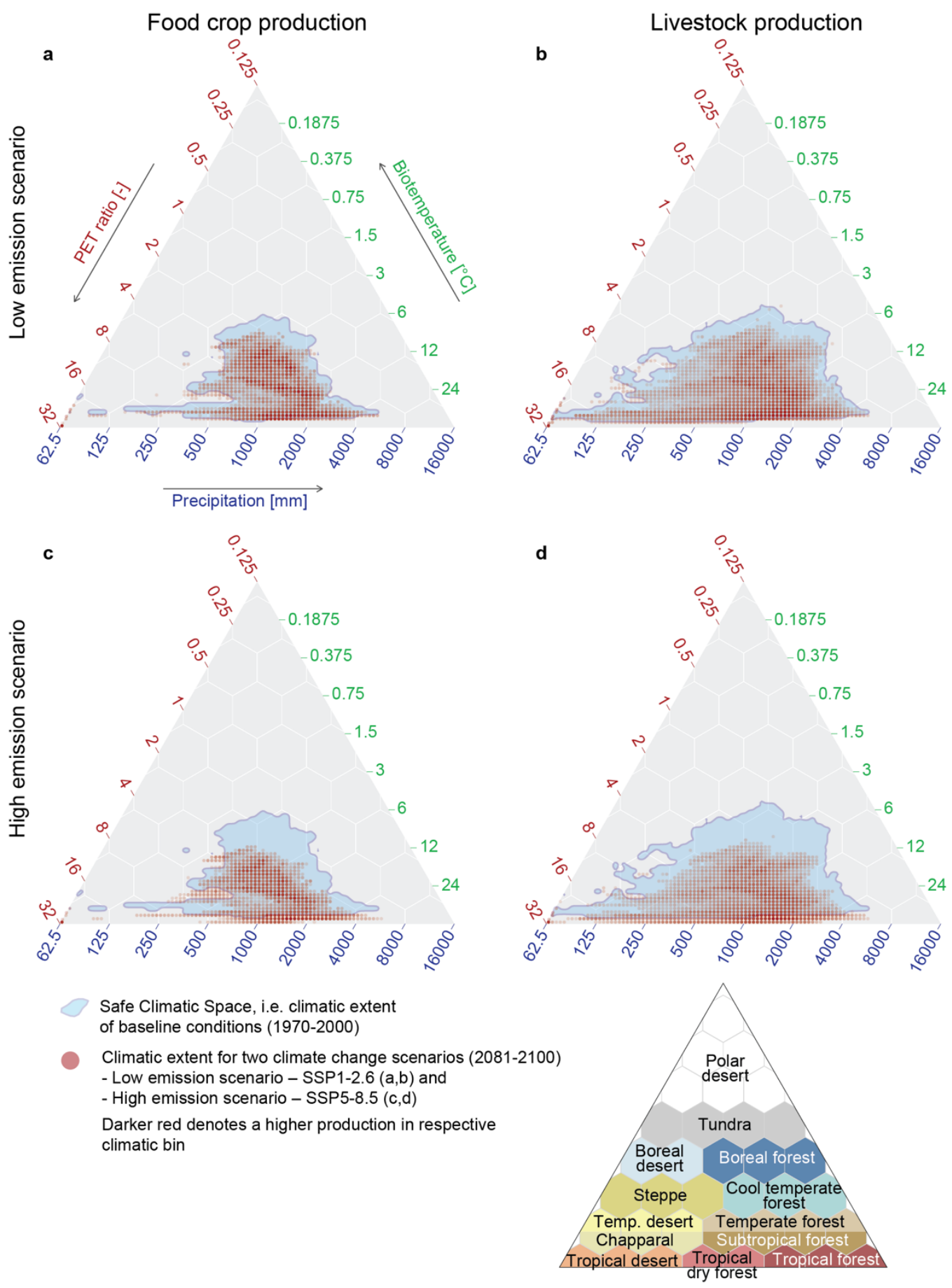

Figure 4. Food crop production $(a, c)$ and livestock production $(b, d)$ mapped to the Holdridge variables for the 198 low emission scenario - SSP1-2.6 (a, b) and high emission scenario-SSP5-8.5 (c, d) for 2081-2100. Light blue 199 denotes the 'Safe Climatic Space', i.e., the baseline climatic conditions in which 95\% of highest livestock and crop production areas are currently located (Methods, Supplementary Fig. 3). The transparency of the red dots illustrates the amount (higher saturation means larger amount) of livestock and crop production under the future climatic conditions (equally 95\% of current global livestock and crop production included) in the respective climatological bin. 


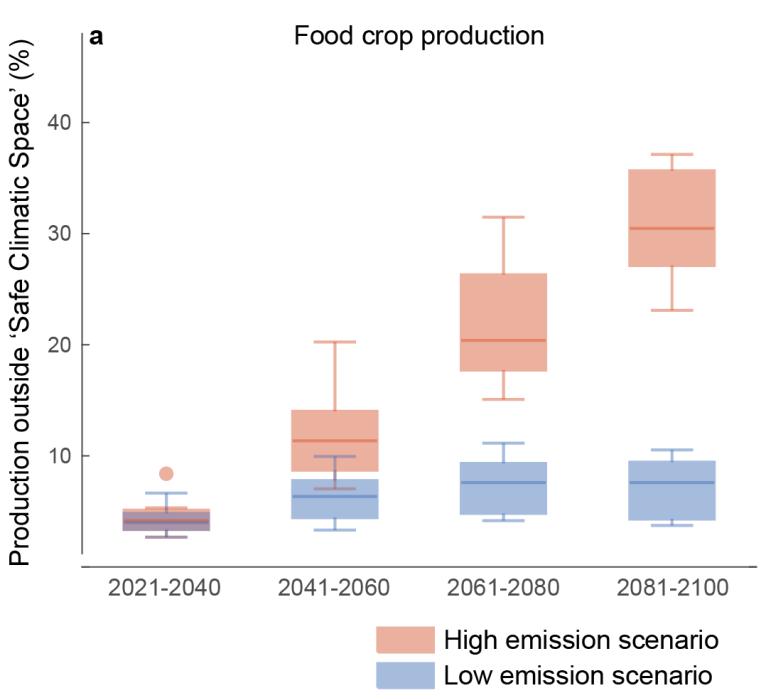
emission scenario (SSP5-8.5).

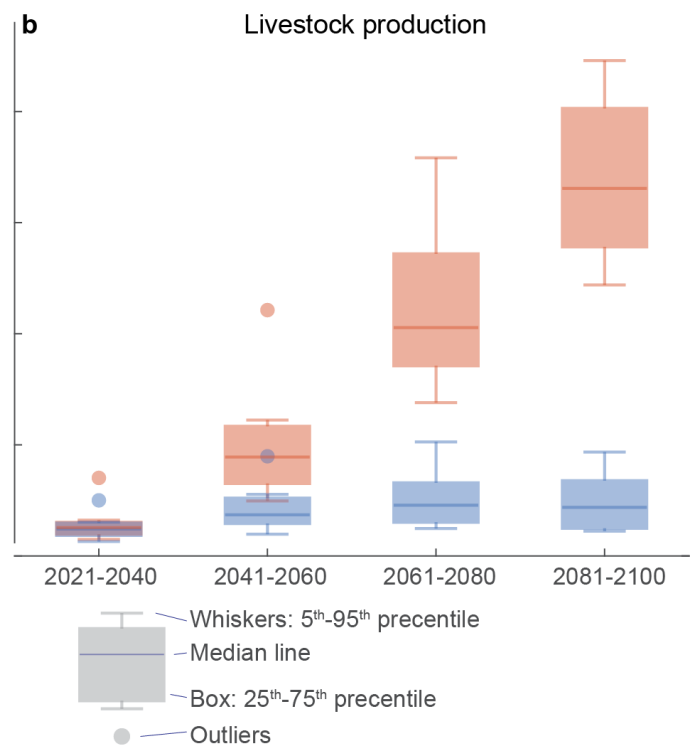

Figure 5. Temporal evolution of global food crop production (a) and livestock production (b) that would fall outside 'Safe Climatic Space' (SCS), i.e., climatic conditions where the majority (95\%) of livestock or food production exist within baseline conditions. The boxplots show the proportion of global livestock and crop production falling outside 'Safe Climatic Space' across the 8 GCMs (see Methods) for years 2021-2040, 20412060, 2061-2080 and 2081-2100. Results are shown for both low emission scenario (SSP1-2.6) and high

\section{Food crop production}

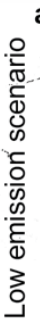

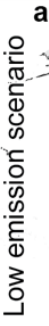

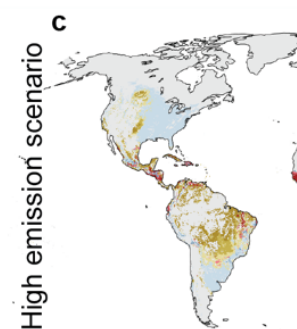

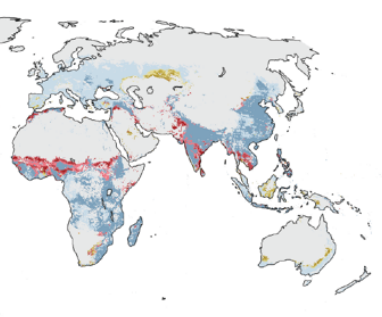

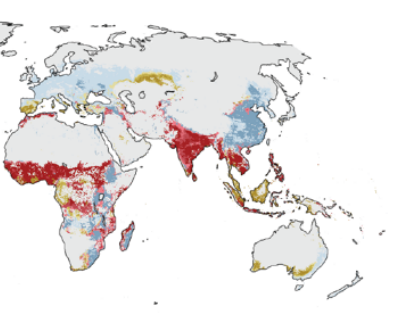

b

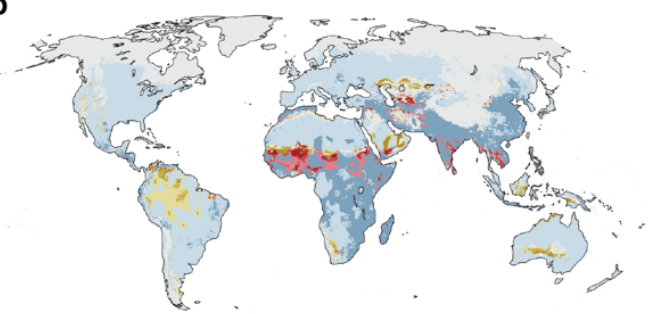

d

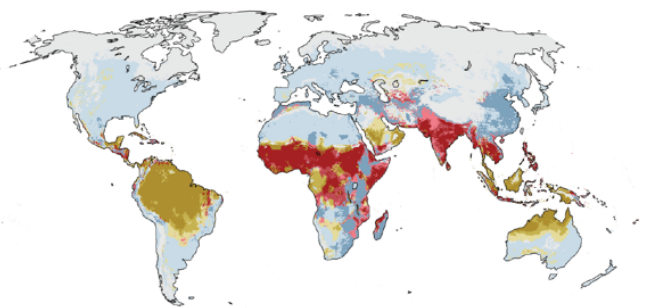

Areas within and outside Safe Climatic Space

212 Figure 6. Extent of food crop production $(a, c)$ and livestock production $(b, d)$ that would fall within and outside 213 'Safe Climatic Space', i.e., climatic conditions where the majority (95\%) of crop or livestock production exist 214 within baseline conditions. 'No or low production' areas refer to the remaining 5\% of the respective areas. Low 215 resilience refers to the bottom $25^{\text {th }}$ percentile of resilience (see Supplementary Fig. 5d). Results are presented 216 separately for low emission scenario (SSP1-2.6) (a, b) and high emission scenario (SSP5-8.5) (c, d). The 217 likelihood categories of crop and livestock production falling outside SCS were determined based on the 218 number of Global Circulation Models (GCMs) (8 in total) showing that the SCS is left: 0 (very likely inside), 1-3 219 (likely inside), 4-6 (potentially outside), 7-8 (likely outside). See tabulated results in Supplementary Table 7. 


\section{Discussion: call for novel multi-sectoral approaches}

221 Our findings reinforce the existing research ${ }^{17,36,37}$ in suggesting that climate change forces humanity into a new era of reduced validity of past experiences and dramatically increased uncertainties. Whereas changes are expected in all climatic zones across the planet (Fig. 1), we were able to detect crop and livestock production areas that would fall outside the Safe Climatic Space (SCS), while highlighting areas which are at highest risk due to their concurrent low resilience (Fig. 6). The ability of individual countries to face these predicted changes and their potential effects, such as environmental refugees ${ }^{38}$ and growing importance of international food trade in conditions where local food production cannot meet the demand ${ }^{39}$.

We further highlight the drastic differences in the impacts on food production between low and high emission scenarios, stressing the importance to remain within the limits of the Paris agreement. These impacts of changes in climatic conditions on food production will likely be amplified by other factors, such as population growth ${ }^{40}$, land degradation ${ }^{38}$ and other environmental challenges related to sustainable food production ${ }^{41}$ as well as increased risk on climate extremes ${ }^{42,43}$. Alarmingly, the same areas where food production has the highest risk of falling beyond SCS are projected to increase their population $^{40}$, and thus food demand, during this century. The predicted increase in desert areas (Supplementary Table 1) will potentially also alter the local biogeochemical processes that are strongly controlled by water and temperature ${ }^{44,45}$. Additionally, an increasing asynchrony of growing season and water availability will likely have additional effects on biodiversity and food production ${ }^{46}$. These potential impacts illustrate well the multifaceted effects that greatly challenge global food production, quality of food, and food prices, among many other issues ${ }^{47}$.

Therefore, it would be highly important to consider these additional factors in future research, by integrating those into the analysis presented here. This would, however, require tools and models that are outside the scope of our approach. Further, many of these factors, such as future changes in climate variability and climate extremes, remain uncertain in global circulation models ${ }^{48,49}$ and thus cannot yet be included in the analysis. Further, we acknowledge that using the food production distribution of 2010 limits the analysis on how future changes would impact on current production areas. While this does not take into account the potential changes in the areas where food is produced or the impact of climate change on yields, it illustrates well the current production areas which might face an elevated risk under future conditions. Further, while the inclusion of scenarios of future food production impacts would be important, the high uncertainty of the scenario available for 2081-2100 ref $^{11}$, led us to leave those for future studies. change as well as increase resilience in food systems ${ }^{50-52}$ and societies ${ }^{33}$, increase the food production sustainability that respects key planetary boundaries ${ }^{41}$, adapt to climate change by, for example, crop 
255 migration $^{53}$ and foster local livelihoods in the most critical areas. All this calls for global partnerships 256 and solidarity, as well as innovative cross-sectoral thinking for finding the needed solutions. Our 257 analyses should thus be linked to other sectors in future studies, to first better understand the 258 cumulative pressure on different sectors in future scenarios, and then seeking the future opportunities 259 to secure sustainable development and equity. 


\section{Experimental Procedures}

\section{Resource Availability}

262 Further information and requests for resources and reagents should be directed to and will be fulfilled

263 by the Lead Contact, Matti Kummu (matti.kummu@aalto.fi)

264 Materials Availability: all datasets generated in this study have been deposited to [repository to be

265 specified upon publication]

266 Data and Code Availability: The code generated during this study are available at [link to git will be

267 specified upon publication].

\section{Data}

269 HLZ (i.e. Holdridge Life Zone) is an ensemble of originally 38 life zones that were merged here to 13 270 zones (following Leemans ${ }^{30}$ and further combining two tropical forest classes) (Figure 1d). HLZs are 271 based on the following variables: annual precipitation, ratio between average annual potential 272 evapotranspiration (PET) ratio and precipitation (aridity indicator), and biotemperature (see maps in

273 Supplementary Fig. 1) using data from WorldClim v2.1, based on approximately 9000 and 60000

274 weather stations ${ }^{35}$. HLZs are especially useful for assessing spatiotemporal and climatic changes

275 locally. To estimate the current and future distribution of these zones, we calculated the parameters

276 needed for determining the HLZ based on open access WorldClim v2.1 dataset ${ }^{35}$ that provides

277 monthly climate data averaged over the baseline period of 1970-2000 as well as future scenarios. We

278 used data for these baseline climate conditions, and future climate change predictions for four 279 timesteps: 2021-2040, 2041-2060, 2061-2080, and 2081-2100. All these were based on eight Global

280 Circulation Models (GCMs) and two climate change scenarios on both extremes (i.e., low emission 281 scenario SSP1-2.6 and high emission scenario SSP5-8.5) under the most recent CMIP6 framework.

282 The GCMs included are as follows: BCC-CSM2-MR, CNRM-CM6-1, CNRM-ESM2-1, CanESM5, 283 IPSL-CM6A-LR, MIROC-ES2L, MIROC6, MRI-ESM2-0.

284 All data were downloaded from WorldClim ${ }^{35}$ with 5 arc-min resolution (or $\sim 10 \mathrm{~km}$ at the equator).

285 The data were downscaled and bias corrected by WorldClim ${ }^{35}$ (more information about the methods is 286 available at https://www.worldclim.org/data/downscaling.html).

287 For assessing the potential impacts of climate change on food production, we used openly available 288 global spatial datasets. For crop production, we used the total crop production data $\mathrm{SPAM}^{31}$ that 289 include altogether 27 major food crops (we intentionally left out 15 non-food crops labelled as non290 food crops in the SPAM data ${ }^{31}$, including for example sugarcane and sugar beet) for year 2010 with 291 resolution of 5 arc-min. 
For distribution of livestock production, we used Gridded Livestock of the World (GLW3) ${ }^{32}$ data for year 2010 with its original resolution of 5 arc-min. We combined the major types of livestock (cattle,

294 sheep, goats, pigs, chickens, horses, buffalo) to Animal Units (AU) following Holecheck et $\mathrm{al}^{54}$ and $295 \quad$ FAO $^{55}$ :

- Cow

- Sheep

- Goat

- Horse

- Buffalo

- Chicken

- Pig
-->1.0 AU

-->0.15 AU

$-->0.10 \mathrm{AU}$

--> $1.8 \mathrm{AU}$

-->0.7 AU

--> $0.01 \mathrm{AU}$

-->0.2 AU

To quantify the resilience of human societies to cope with the future changes, we used the recent resilience concept by Varis et $\mathrm{al}^{33}$. The concept is based on a composite index approach for combining geospatially the adaptive capacity and environment pressure on a global scale for years 1990-2015 (here year 2010 was used to be consistent with crop production and livestock production data), resulting raster maps over the globe's land surface area with a 5 arc-min resolution.

\section{Methods for Holdridge Life Zone calculations}

Annual precipitation $\left[\mathrm{mm} \mathrm{yr}^{-1}\right]$ was calculated from monthly precipitation data, as defined by the HLZ method ${ }^{19}$, directly available from WorldClim v2.1 dataset ${ }^{35}$ (Supplementary Fig. 1).

Biotemperature was calculated based on monthly average temperature. As daily average temperature was not available for future scenarios, we estimated the monthly average temperature as the average of monthly minimum and maximum temperatures. The resulting bias was corrected using mean, minimum and maximum monthly temperatures of the baseline conditions. The months with mean temperature below $0^{\circ} \mathrm{C}$ were omitted from biotemperature calculations, as defined in the method ${ }^{19}$. Note that while in the original method ${ }^{19}$, months with temperatures over $30^{\circ} \mathrm{C}$ were omitted, we did not use this cap. We came to this solution by comparing the PET derived in Holdridge methods from biotemperature (see below, and Supplementary Fig. 2) and the satellite observed PET (i.e., potential evapotranspiration, $\mathrm{mm} \mathrm{yr}^{-1}$ ), and observing that the original PET method (Supplementary Fig. 2a) would not reflect well the observed PET (Supplementary Fig. 2f) in hot and dry areas while the modified PET method, without the $30^{\circ} \mathrm{C}$ cap in biotemperature calculations, would result much more reliable PET (Supplementary Fig. 2b). Once these modifications were done to the temperature datasets, the remaining monthly temperatures $\left[{ }^{\circ} \mathrm{C}\right]$ were averaged over a year. PET was estimated using the method described in Holdridge ${ }^{19}$, i.e., by multiplying biotemperature with a constant value of 58.93. For PET ratio to mean total annual precipitation [-], monthly PET values were summed over a year and then divided by annual precipitation (Supplementary Fig. 1). Finally, we used 
monthly minimum temperature data to map areas without any frost days (i.e., in all months, minimum daily temperature was above $0^{\circ} \mathrm{C}$ ). These frost data were used to delineate temperate zones from subtropical ones (Fig. 1d).

\section{Methods for estimating change in Holdridge Life Zones}

Based on the data introduced above, we were able to define the HLZ for each 5 arc-min gridcell, both for current and future conditions (Fig. 1a-c). We used the original method ${ }^{20}$ to define the life zone, as briefly explained below.

To implement the HLZ diagram computationally, we constructed a version in Cartesian coordinates from precipitation $(\mathrm{P},[\mathrm{mm}])$ and PET ratio (R, [-]) using the thresholds given by Holdridge ${ }^{19}$. Bearing in mind that the HLZ diagram is an isosceles triangle, that its axes are logarithmic and using the ranges of the $\mathrm{P}$ and $\mathrm{R}$ axes, a given value of $\mathrm{P}$ and $\mathrm{R}$ translates into Cartesian coordinates $\mathrm{x}$ and $\mathrm{y}$ (both with value range $[0,1])$ as follows:

$\mathrm{P}^{\prime}=(\log 2(\mathrm{P})-\log 2(62.5 \mathrm{~mm})) /(\log 2(\mathrm{P})-\log 2(16000 \mathrm{~mm})) * 1 / \mathrm{mm}$

$\mathrm{R}^{\prime}=(\log 2(\mathrm{R})-\log 2(0.125)) /(\log 2(\mathrm{R})-\log 2(32))$

$\mathrm{x}=0.5 *(1+\mathrm{P}-\mathrm{R})$

$y=1-P-R$

Once we had the cartesian coordinates for each gridcell, we were able to assign a Holdridge class to each cell. This was then used to estimate the change in future RCP scenarios. To estimate the change, we used the ensemble median of the 8 GCMs (see above) and instead of just mapping the cells where the HLZ class would change, we calculated the distance between the current and future location (see Supplementary Fig. 6a) as well as the direction of change. With the distance, we were able to estimate the magnitude of the change in absolute terms, and when dividing that with mean distance between the two HLZ centroids we got the relative change. The direction of change, in turn, indicates whether the change is mainly due to higher biotemperature, wetter conditions or larger PET ratio (see Supplementary Fig. 6b).

\section{Methods for spatial assessments}

To extract spatial patterns about the changes in HLZs, for each raster cell, we scaled the change between current and future HLZ coordinates by dividing with the distance between two HLZ centroids. Hence, a change of one means that the observed change in the HLZ coordinates is equal to the difference between two HLZ centroids. The scaled HLZ change values were also divided into classes based on weighted percentiles: 0-25\% (low), 25-50\% (moderate), 50-75\% (high), $75-100 \%$ (very high). 
359 To map the most critical areas with low capacity to cope with future changes, we used an indicator for

360 resilience ${ }^{33}$. For this purpose, the resilience data ${ }^{33}$ (Supplementary Fig. 5c), ranging between -1 and 1 ,

361 was divided into area weighted percentiles (Supplementary Fig. 5d), similarly to the HLZ data.

362 After dividing the HLZ change and resilience values into the four percentile classes, we compared

363 them to crop production in $\mathrm{kcal}^{31}$ (Supplementary Fig. 5a) and livestock production in animal units

364 (see above) (Supplementary Fig. 5b). Namely, we analysed how the extent of livestock and crop

365 productions relate to the changes in the HLZs and resilience. The analysis was conducted by summing

366 the respective production data that fall into each of the HLZ change and resilience classes leading to

$367 \quad 16$ classes in total.

\section{Safe Climatic Space}

369 We further assessed and estimated the crop and livestock production areas under risk of falling

370 outside the corresponding SCSs (Safe Climatic Spaces), i.e., moving beyond climatic conditions

371 where the majority (95\%) of the food is currently produced under baseline conditions. To define and

372 map the SCSs, we first placed each grid cell with, for example food crop production to the Holdridge

373 triangle (Fig. 1d) using the baseline bio-temperature, precipitation and aridity climatic conditions.

374 Once we had placed all the food crop production areas in the triangle, we got a cloud of the climatic

375 conditions where food crops are produced (see red dots in Supplementary Fig. 3a). From this cloud of

376 points, we filtered out the 5\% smallest crop production areas, leaving the SCS area covering $95 \%$ of

377 crop production (see blue area in Supplementary Fig. 3a). Thus, the SCS is defined as the climatic

378 space where $95 \%$ of crop production takes place. The calculations were conducted similarly for

379 livestock production (Supplementary Fig. 3b).

380 Then we compared the future climatic conditions of these major production areas, and estimated

381 which would fall beyond the SCS under both emission scenarios. Finally, utilizing simulation results

382 across the eight GCMs, the likelihood of falling beyond SCS were mapped for each grid cell, as well

383 as aggregated to national level. 


\section{Acknowledgements}

385 M.K. received financial support from the Academy of Finland projects WASCO (grant no. 305471),

386 WATVUL (grant no. 317320) and TREFORM (grant no. 339834), the Academy of Finland SRC

387 project 'Winland', the Emil Aaltonen foundation project 'eat-less-water', and European Research

388 Council (ERC) under the European Union's Horizon 2020 research and innovation programme (grant

389 agreement No. 819202). MH and MT received financial support from Maa- ja vesitekniikan tuki ry.

390 MH was also supported by the AaltoENG doctoral programme. We appreciate the help of Johannes

391 Piipponen with livestock production data.

\section{Author Contributions}

393 MK, DV, MH designed the research with support from all co-authors. MK, DV compiled the

394 Holdridge Life Zone mapping. MH, MK performed the spatial analyses with support from DV. MK

395 led the writing of the manuscript with contributions from all co-authors.

\section{Competing Interests statement}

397 We declare no competing financial interests. 


\section{References}

1. Scheffer, M., Carpenter, S., Foley, J.A., Folke, C., and Walker, B. (2001). Catastrophic shifts in ecosystems. Nature 413, 591-596.

2. Rockström, J., Steffen, W., Noone, K., Persson, A., Chapin, F.S., Lambin, E.F., Lenton, T.M., Scheffer, M., Folke, C., Schellnhuber, H.J., et al. (2009). A safe operating space for humanity. Nature $461,472-475$.

3. Smith, B.D., and Zeder, M.A. (2013). The onset of the Anthropocene. Anthropocene 4, 8-13.

4. Lobell, D.B., and Field, C.B. (2007). Global scale climate-crop yield relationships and the impacts of recent warming. Environ. Res. Lett. 2, 014002.

5. Arnell, N.W., Brown, S., Gosling, S.N., Gottschalk, P., Hinkel, J., Huntingford, C., LloydHughes, B., Lowe, J.A., Nicholls, R.J., Osborn, T.J., et al. (2016). The impacts of climate change across the globe: A multi-sectoral assessment. Climatic Change 134, 457-474.

6. IPCC (2014). Climate Change 2014: Synthesis Report. Contribution of Working Groups I, II and III to the Fifth Assessment Report of the Intergovernmental Panel on Climate Change [Core Writing Team, R.K. Pachauri and L.A. Meyer (eds.)] (IPCC).

7. Lipper, L., Thornton, P., Campbell, B.M., Baedeker, T., Braimoh, A., Bwalya, M., Caron, P., Cattaneo, A., Garrity, D., Henry, K., et al. (2014). Climate-smart agriculture for food security. Nature Clim Change 4, 1068-1072.

8. Porter, J.R., and Semenov, M.A. (2005). Crop responses to climatic variation. Philosophical Transactions of the Royal Society B: Biological Sciences 360, 2021-2035.

9. Schewe, J., Heinke, J., Gerten, D., Haddeland, I., Arnell, N.W., Clark, D.B., Dankers, R., Eisner, S., Fekete, B.M., Colón-González, F.J., et al. (2014). Multimodel assessment of water scarcity under climate change. Proceedings of the National Academy of Sciences 111, 3245-3250.

10. Ramankutty, N., Foley, J.A., Norman, J., and McSweeney, K. (2002). The global distribution of cultivable lands: current patterns and sensitivity to possible climate change. Global Ecol Biogeogr 11, 377-392.

11. Rosenzweig, C., Elliott, J., Deryng, D., Ruane, A.C., Müller, C., Arneth, A., Boote, K.J., Folberth, C., Glotter, M., Khabarov, N., et al. (2014). Assessing agricultural risks of climate change in the 21st century in a global gridded crop model intercomparison. Proceedings of the National Academy of Sciences 111, 3268-3273.

12. Zabel, F., Putzenlechner, B., and Mauser, W. (2014). Global Agricultural Land Resources - A High Resolution Suitability Evaluation and Its Perspectives until 2100 under Climate Change Conditions. PLOS ONE 9, e107522.

13. Lobell, D.B., Schlenker, W., and Costa-Roberts, J. (2011). Climate Trends and Global Crop Production Since 1980. Science 333, 616.

14. Pugh, T.A.M., Müller, C., Elliott, J., Deryng, D., Folberth, C., Olin, S., Schmid, E., and Arneth, A. (2016). Climate analogues suggest limited potential for intensification of production on current croplands under climate change. Nature Communications 7, 12608. 
15. Asseng, S., Ewert, F., Martre, P., Rötter, R.P., Lobell, D.B., Cammarano, D., Kimball, B.A., Ottman, M.J., Wall, G.W., White, J.W., et al. (2015). Rising temperatures reduce global wheat production. Nature Climate Change 5, 143-147.

16. Deryng, D., Conway, D., Ramankutty, N., Price, J., and Warren, R. (2014). Global crop yield response to extreme heat stress under multiple climate change futures. Environmental Research Letters 9, 034011.

17. Xu, C., Kohler, T.A., Lenton, T.M., Svenning, J.-C., and Scheffer, M. (2020). Future of the human climate niche. PNAS.

18. Steffen, W., Richardson, K., Rockström, J., Cornell, S.E., Fetzer, I., Bennett, E.M., Biggs, R., Carpenter, S.R., de Vries, W., de Wit, C.A., et al. (2015). Planetary boundaries: Guiding human development on a changing planet. Science $347,1259855$.

19. Holdridge, L.R. (1947). Determination of World Plant Formations From Simple Climatic Data. Science $105,367-368$.

20. Holdridge, L.R. (1967). Life zone ecology. Life zone ecology.

21. Derner, J., Briske, D., Reeves, M., Brown-Brandl, T., Meehan, M., Blumenthal, D., Travis, W., Augustine, D., Wilmer, H., Scasta, D., et al. (2018). Vulnerability of grazing and confined livestock in the Northern Great Plains to projected mid- and late-twenty-first century climate. Climatic Change 146, 19-32.

22. Mbow, C., Rosenzweig, C., Barioni, L.G., Benton, T.G., Herrero, M., Krishnapillai, M., Liwenga, E., Pradhan, P., Rivera-Ferre, M.G., Sapkota, T., et al. (2019). Food Security. In Climate Change and Land: an IPCC special report on climate change, desertification, land degradation, sustainable land management, food security, and greenhouse gas fluxes in terrestrial ecosystems [P.R. Shukla, J. Skea, E. Calvo Buendia, V. Masson-Delmotte, H.-O. Pörtner, D.C. Roberts, P. Zhai, R. Slade, S. Connors, R. van Diemen, M. Ferrat, E. Haughey, S. Luz, S. Neogi, M. Pathak, J. Petzold, J. Portugal Pereira, P. Vyas, E. Huntley, K. Kissick, M. Belkacemi, J. Malley, (eds.)].

23. Ray, D.K., Gerber, J.S., MacDonald, G.K., and West, P.C. (2015). Climate variation explains a third of global crop yield variability. Nature Communications 6, 5989.

24. Brown, S., Gillespie, A.J.R., and Lugo, A.E. (1989). Biomass Estimation Methods for Tropical Forests with Applications to Forest Inventory Data. for sci 35, 881-902.

25. Post, W.M., Emanuel, W.R., Zinke, P.J., and Stangenberger, A.G. (1982). Soil carbon pools and world life zones. Nature 298, 156-159.

26. Emanuel, W.R., Shugart, H.H., and Stevenson, M.P. (1985). Climatic change and the broad-scale distribution of terrestrial ecosystem complexes. Climatic Change 7, 29-43.

27. Kottek, M., Grieser, J., Beck, C., Rudolf, B., and Rubel, F. (2006). World Map of the KöppenGeiger climate classification updated. https://www.ingentaconnect.com/content/schweiz/mz/2006/00000015/00000003/art00001\#.

28. Chakraborty, A., Joshi, P.K., Ghosh, A., and Areendran, G. (2013). Assessing biome boundary shifts under climate change scenarios in India. Ecological Indicators 34, 536-547.

29. Szelepcsényi, Z., Breuer, H., Kis, A., Pongrácz, R., and Sümegi, P. (2018). Assessment of projected climate change in the Carpathian Region using the Holdridge life zone system. Theor Appl Climatol 131, 593-610. 
30. Leemans, R. (1990). Possible Changes in Natural Vegetation Patterns due to Global Warming.

31. Yu, Q., You, L., Wood-Sichra, U., Ru, Y., Joglekar, A.K.B., Fritz, S., Xiong, W., Lu, M., Wu, W., and Yang, P. (2020). A cultivated planet in 2010 - Part 2: The global gridded agriculturalproduction maps. Earth System Science Data 12, 3545-3572.

32. Gilbert, M., Nicolas, G., Cinardi, G., Van Boeckel, T.P., Vanwambeke, S.O., Wint, G.R.W., and Robinson, T.P. (2018). Global distribution data for cattle, buffaloes, horses, sheep, goats, pigs, chickens and ducks in 2010. Scientific Data 5, 180227.

33. Varis, O., Taka, M., and Kummu, M. (2019). The Planet's Stressed River Basins: Too Much Pressure or Too Little Adaptive Capacity? Earth's Future 7, 1118-1135.

34. Halasz, P. (2007). Holdridge Life Zone Classification scheme. Available at https://commons. wikimedia.org/w/index.php?curid=1737503).

35. Fick, S.E., and Hijmans, R.J. (2017). WorldClim 2: new 1-km spatial resolution climate surfaces for global land areas. International Journal of Climatology 37, 4302-4315.

36. Whitmee, S., Haines, A., Beyrer, C., Boltz, F., Capon, A.G., Dias, B.F. de S., Ezeh, A., Frumkin, H., Gong, P., Head, P., et al. (2015). Safeguarding human health in the Anthropocene epoch: report of The Rockefeller Foundation-Lancet Commission on planetary health. The Lancet 386, 1973-2028.

37. Piontek, F., Müller, C., Pugh, T.A.M., Clark, D.B., Deryng, D., Elliott, J., González, F. de J.C., Flörke, M., Folberth, C., Franssen, W., et al. (2014). Multisectoral climate impact hotspots in a warming world. PNAS 111, 3233-3238.

38. IPBES (2018). The IPBES assessment report on land degradation and restoration. Montanarella, L., Scholes, R., and Brainich, A. (eds.). (Secretariat of the Intergovernmental Science-Policy Platform on Biodiversity and Ecosystem Services).

39. Porkka, M., Guillaume, J., Siebert, S., Schaphoff, S., and Kummu, M. (2017). The use of food imports to overcome local limits to growth. Earth's Future 5, 393-407.

40. Jones, B., and O’Neill, B.C. (2016). Spatially explicit global population scenarios consistent with the Shared Socioeconomic Pathways. Environmental Research Letters 11, 084003.

41. Gerten, D., Heck, V., Jägermeyr, J., Bodirsky, B.L., Fetzer, I., Jalava, M., Kummu, M., Lucht, W., Rockström, J., Schaphoff, S., et al. (2020). Feeding ten billion people is possible within four terrestrial planetary boundaries. Nature Sustainability 3, 200-208.

42. Nangombe, S., Zhou, T., Zhang, W., Wu, B., Hu, S., Zou, L., and Li, D. (2018). Record-breaking climate extremes in Africa under stabilized $1.5^{\circ} \mathrm{C}$ and $2{ }^{\circ} \mathrm{C}$ global warming scenarios. Nature Clim Change 8, 375-380.

43. King, A.D., Karoly, D.J., and Henley, B.J. (2017). Australian climate extremes at $1.5^{\circ} \mathrm{C}$ and $2{ }^{\circ} \mathrm{C}$ of global warming. Nature Clim Change 7, 412-416.

44. Hamilton, S.K. (2010). Biogeochemical implications of climate change for tropical rivers and floodplains. Hydrobiologia 657, 19-35.

45. Chapin III, F.S., McFarland, J., McGuire, A.D., Euskirchen, E.S., Ruess, R.W., and Kielland, K. (2009). The changing global carbon cycle: linking plant-soil carbon dynamics to global consequences. Journal of Ecology 97, 840-850. 
46. Austin, A.T., Yahdjian, L., Stark, J.M., Belnap, J., Porporato, A., Norton, U., Ravetta, D.A., and Schaeffer, S.M. (2004). Water pulses and biogeochemical cycles in arid and semiarid ecosystems. Oecologia 141, 221-235.

47. Vermeulen, S.J., Campbell, B.M., and Ingram, J.S.I. (2012). Climate Change and Food Systems. Annu. Rev. Environ. Resour. 37, 195-222.

48. Di Luca, A., Pitman, A.J., and de Elía, R. (2020). Decomposing Temperature Extremes Errors in CMIP5 and CMIP6 Models. Geophysical Research Letters 47, e2020GL088031.

49. Seneviratne, S.I., and Hauser, M. (2020). Regional Climate Sensitivity of Climate Extremes in CMIP6 Versus CMIP5 Multimodel Ensembles. Earth's Future 8, e2019EF001474.

50. Nyström, M., Jouffray, J.-B., Norström, A.V., Crona, B., Jørgensen, P.S., Carpenter, S.R., Bodin, Ö., Galaz, V., and Folke, C. (2019). Anatomy and resilience of the global production ecosystem. Nature $575,98-108$.

51. Seekell, D., Carr, J., Dell'Angelo, J., D’Odorico, P., Fader, M., Gephart, J., Kummu, M., Magliocca, N., Porkka, M., Puma, M., et al. (2017). Resilience in the global food system. Environmental Research Letters 12, 025010.

52. Kummu, M., Kinnunen, P., Lehikoinen, E., Porkka, M., Queiroz, C., Röös, E., Troell, M., and Weil, C. (2020). Interplay of trade and food system resilience: Gains on supply diversity over time at the cost of trade independency. Global Food Security 24, 100360.

53. Sloat, L.L., Davis, S.J., Gerber, J.S., Moore, F.C., Ray, D.K., West, P.C., and Mueller, N.D. (2020). Climate adaptation by crop migration. Nat Commun 11, 1-9.

54. Holechek, J., Pieper, R.D., and Herbel, C.H. (2010). Range management : principles and practices, Sixth edition. ed. Prentice Hall, Upper Saddle River, N.J. : London.

55. FAO (2011). Guidelines for the Preparation of Livestock Sector Reviews. Animal Production and Health Guidelines. No. 5. Rome. [WWW Document]. URL http://www.fao.org/3/i2294e/i2294e00.htm. 


\section{Supplementary figures and tables}

Kummu et al: Climate change risks to push one-third of global food production outside Safe Climatic Space.
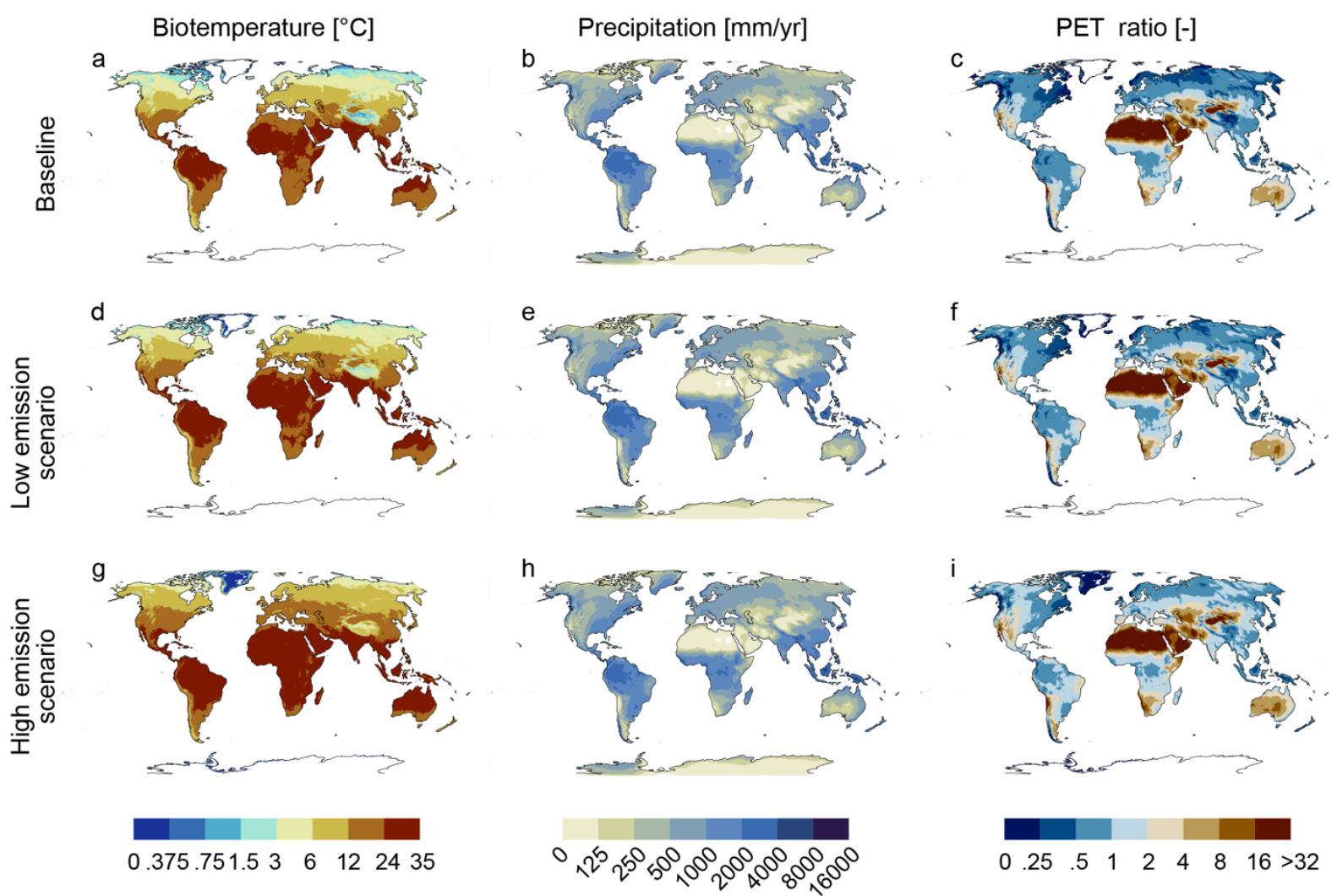

Supplementary Figure 1. Three components used to estimate Holdridge Life Zones, biotemperature (a, d, g), precipitation $(b, e, h)$ and potential evapotranspiration ratio (c, f, i). Each mapped for baseline conditions 1970-2000 (a-c), for 2081-2100 under low emission scenario (SSP1-2.6) (d-f) and under high emission scenario (SSP5-8.5) (g-i). Data used to calculate these is from WorldClim v2.1 $\mathrm{ref}^{1}$. See Methods for how the individual components were calculated. 
a

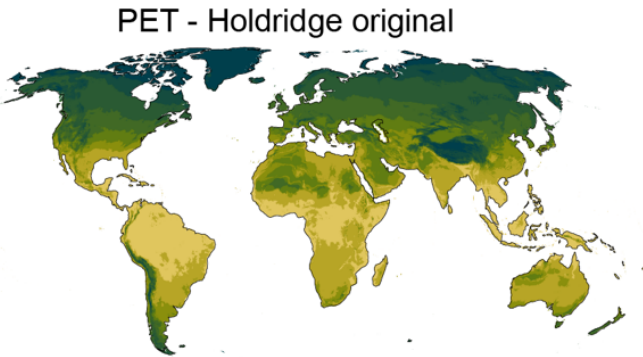

C

PET - Hargreaves

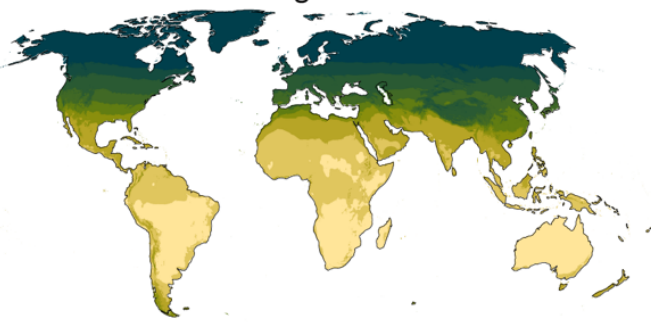

e

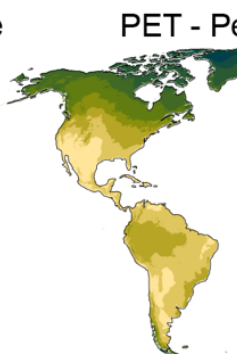

b

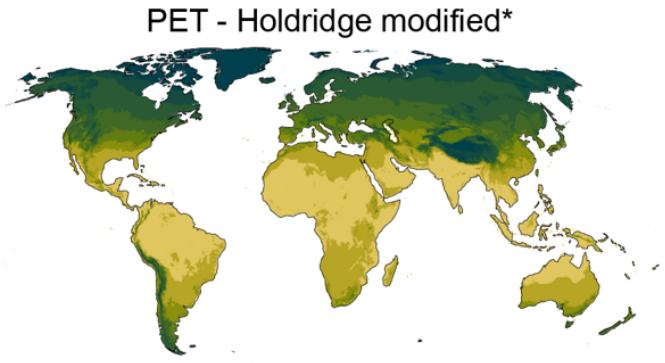

d

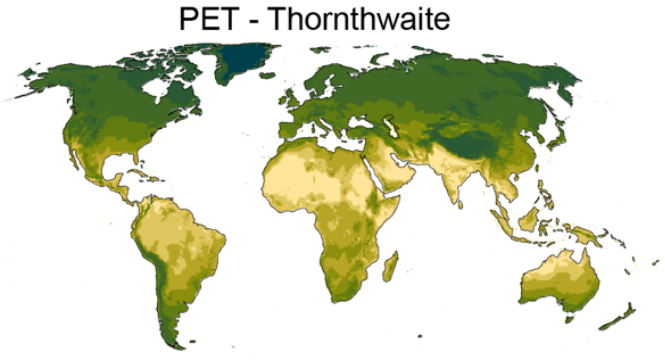

f

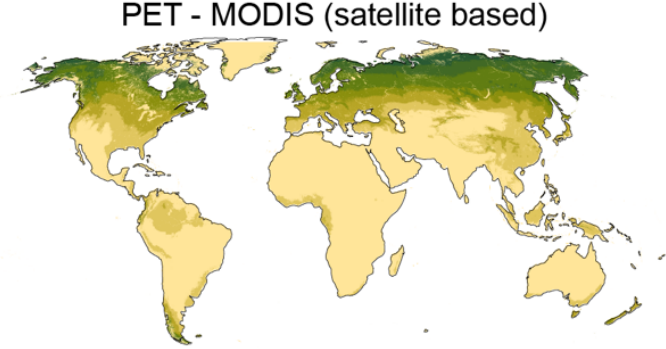

* used in this study

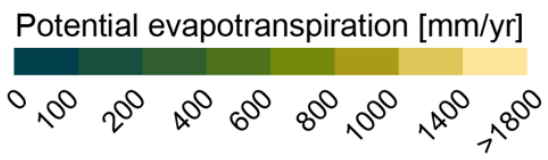

Supplementary Figure 2. Different methods to calculate the potential evapotranspiration (PET). Original Holdridge method (a) can be compared to the modified method used here (see Methods) (b), as well as other methods to estimate PET. Panels a-d were calculated as a part of this study, using data for years 1970-2000 from WorldClim v2.1 ref ${ }^{1}$. Data for PET using the Penman-Monteith method (e) is from Trabucco and Zomer ${ }^{2}$ and satellite-based MODIS estimates from NTSG ${ }^{3}$. 


\section{Food crop production}

a

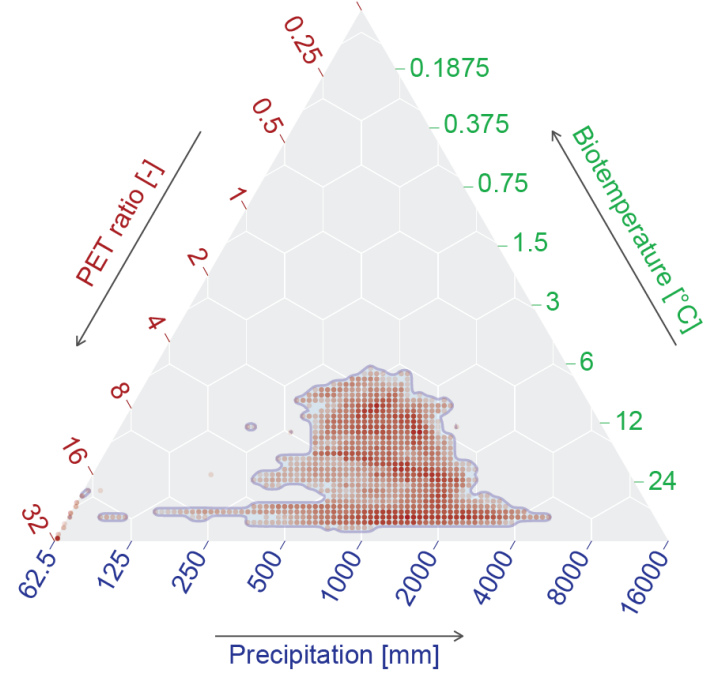

Safe Climatic Space, i.e. climatic extent of baseline conditions (1970-2000)

Climatic extent for baseline conditions (1970-2000) Darker red denotes a higher production in respective climatic bin

\section{Livestock production}
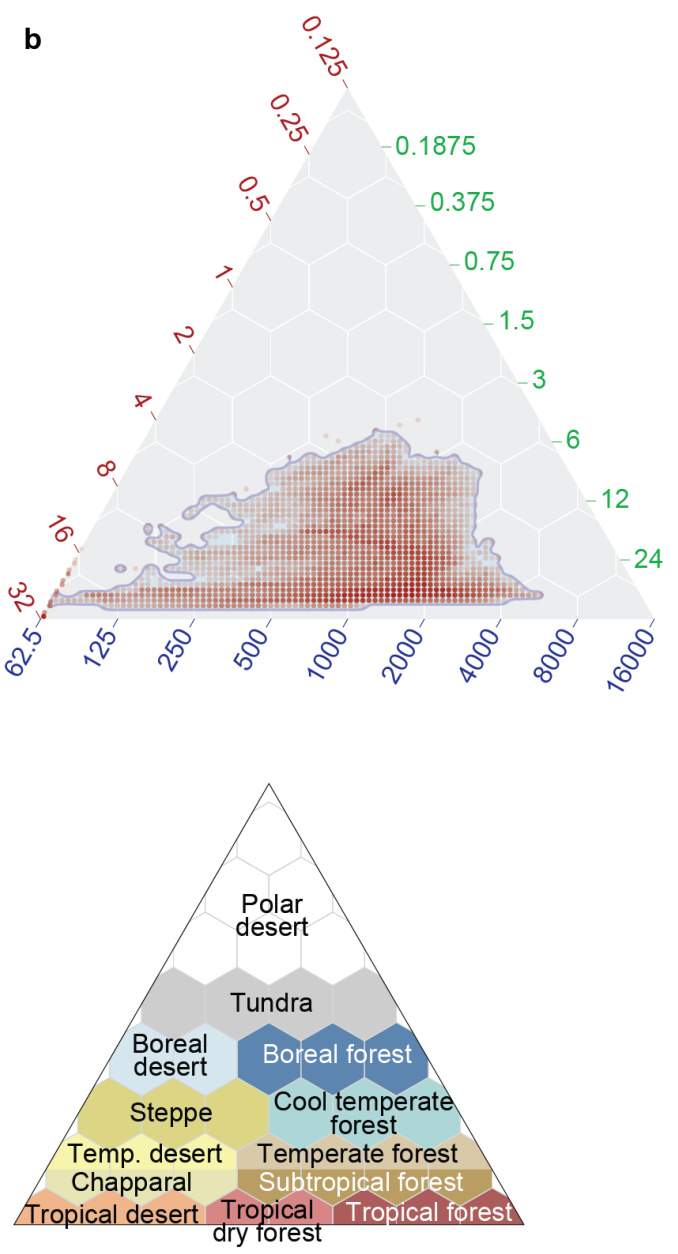

Supplementary Figure 3. Food crop production (a) and livestock production (b) mapped to the Holdridge variables for the baseline conditions 1970-2000. Light blue area denotes the 'Safe Climatic Space', i.e., the climatic conditions for these baseline conditions in which 95\% of largest population and food production areas are located in (Methods). The transparency of the red dots illustrates the amount (higher saturation means larger amount) production under the same baseline conditions (equally $95 \%$ of current global food production included) in the respective climatological bin.

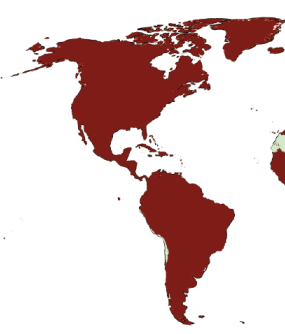

Low emission scenario

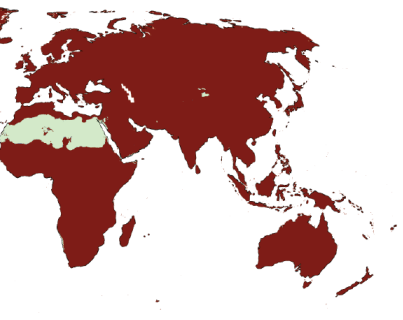

latitudinal wetter b

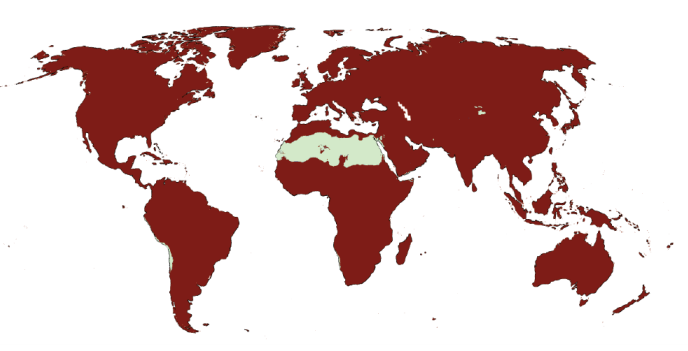

Supplementary Figure 4. Dominant component in Holdridge Life Zone change (see Methods; Supplementary Fig. 6) for 2081-2100 under low emission scenario (SSP1-2.6) (a) and high emission scenario (SSP5-8.5) (b). 

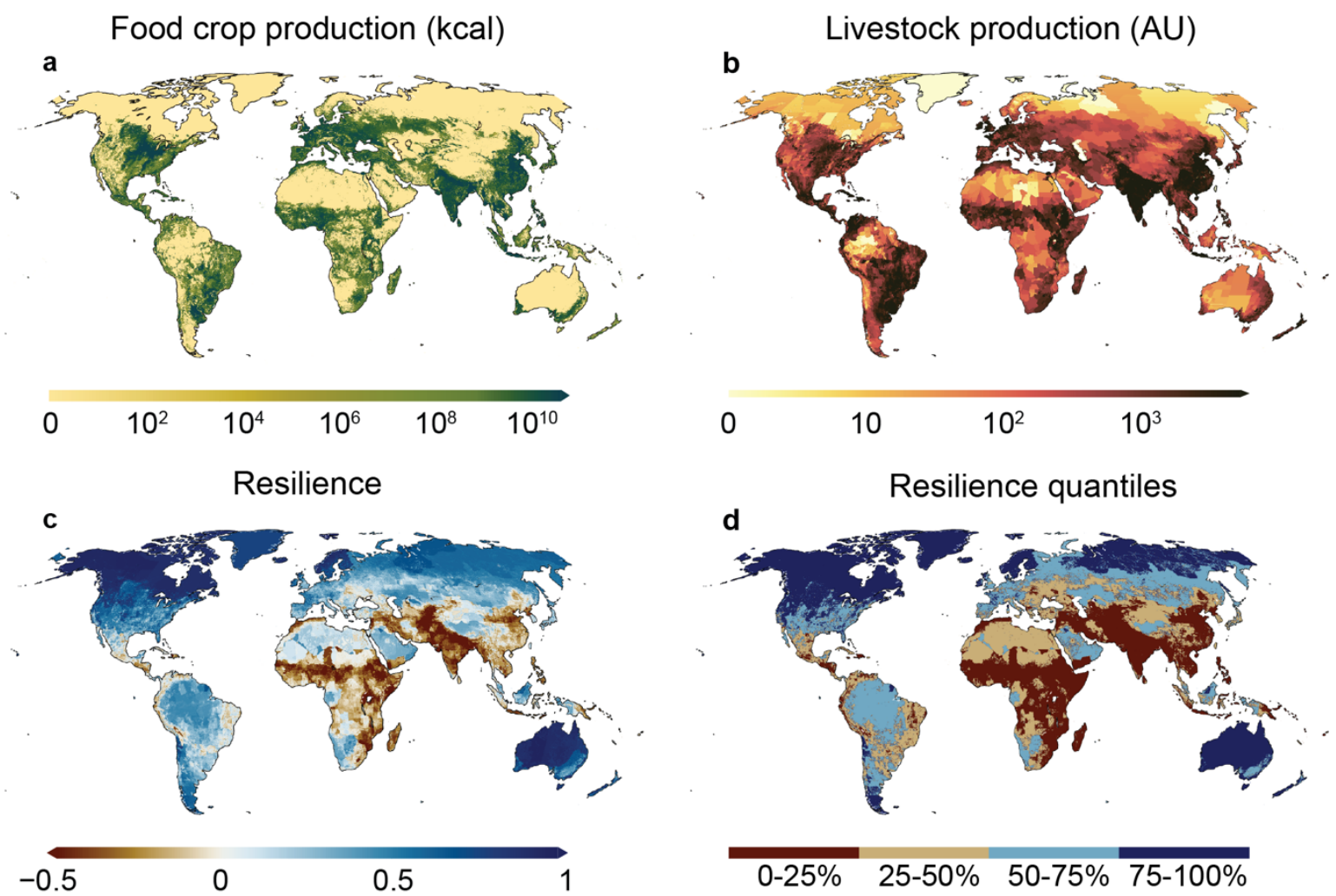

Supplementary Figure 5. Input data of food crop production (a), livestock production (b), and resilience mapped (c,d). Food crop production from SPAM ${ }^{4}$, livestock production from the Gridded Livestock of the World (GLW 3) database and $^{5}$ resilience from Varis et al ${ }^{6}$. AU stands for Animal Units (see Methods). 


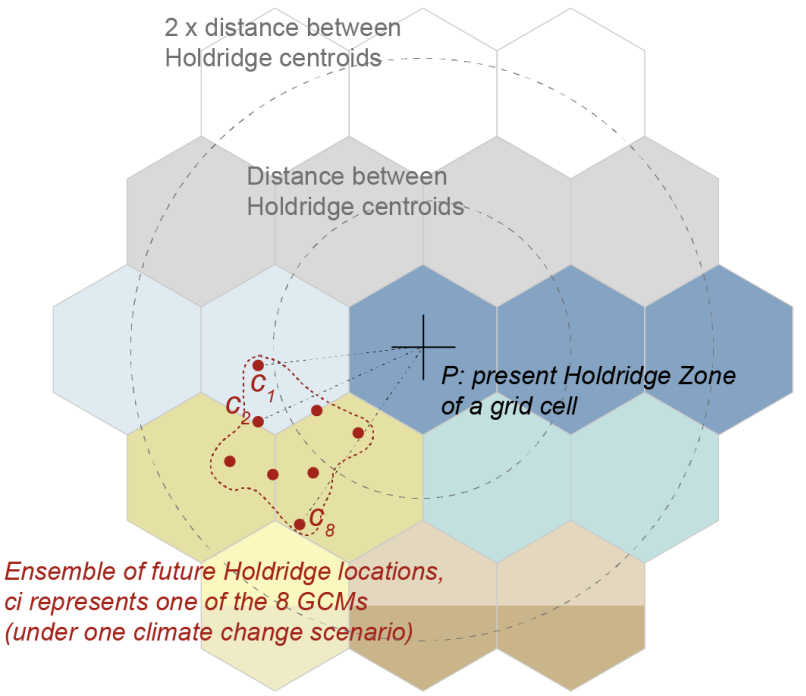

$$
\begin{aligned}
& \text { Ensemble median change: } \\
& \text { - magnitude: median distance between present and } \\
& \text { future Holdridge locations } \\
& \text { - normalised magnitude: magnitude divided by distance } \\
& \text { between Holdridge centroids }
\end{aligned}
$$

- direction of change: median direction of ensemble b Direction of change

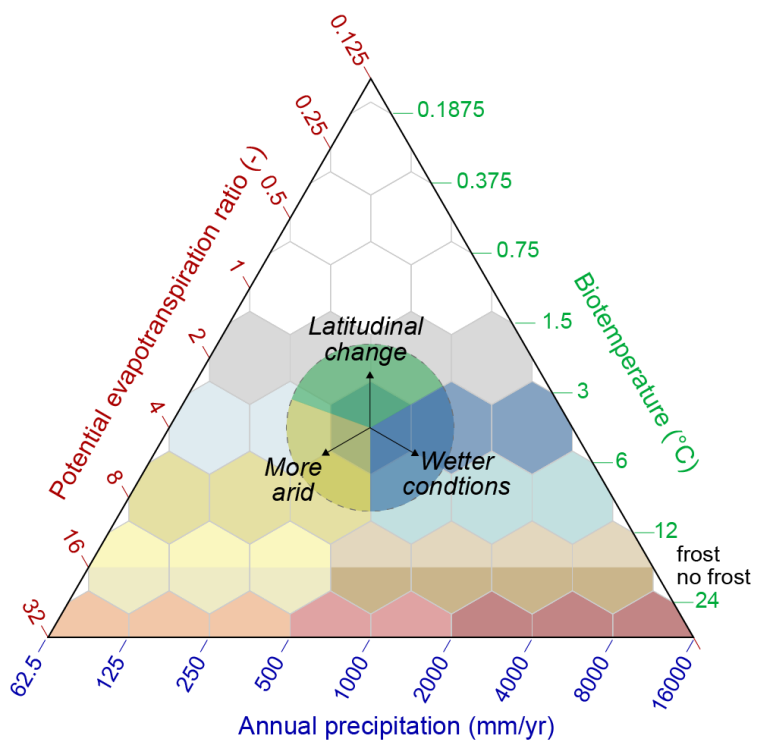

Supplementary Figure 6. Summary of the methods to calculate the ensemble median change. Magnitude of change (a) and direction of change (b). Note: the actual distance and direction calculations were done using cartesian coordinates (see Methods).

Supplementary Table 1. Area in $1000 \mathrm{~km}^{2}$ of Holdridge zones on baseline (1970-2000) as well as future (2081-2100) conditions under low emission scenario (SSP1-2.6) and high emission scenario (SSP5-8.5).

\begin{tabular}{lrrr}
\hline Holdridge Zone & $\begin{array}{r}\text { Baseline } \\
{\left[\mathbf{1 0 0 0} \mathbf{~ k m}^{2}\right]}\end{array}$ & $\begin{array}{r}\text { Low emission } \\
\text { scenario } \\
{\left[\mathbf{1 0 0 0} \mathbf{~ k m}^{2}\right]}\end{array}$ & $\begin{array}{r}\text { High emission } \\
\text { scenario } \\
{\left[\mathbf{1 0 0 0} \mathbf{~ k m}^{2}\right]}\end{array}$ \\
\hline Polar Desert & 16,464 & $13,779(-16.3 \%)$ & $12,370(-24.9 \%)$ \\
Tundra & 9,131 & $5,572(-39.0 \%)$ & $2,329(-74.5 \%)$ \\
Boreal Desert & 911 & $2,354(+158.5 \%)$ & $1,594(+75.0 \%)$ \\
Boreal Forest & 18,513 & $14,760(-20.3 \%)$ & $8,028(-56.6 \%)$ \\
Steppe & 10,743 & $11,056(+2.9 \%)$ & $9,259(-13.8 \%)$ \\
Cool Temperate Forest & 12,301 & $14,957(+21.6 \%)$ & $15,911(+29.4 \%)$ \\
Temperate Desert & 3,819 & $4,719(+23.6 \%)$ & $8,029(+110.2 \%)$ \\
Temperate Forest & 3,368 & $4,984(+48.0 \%)$ & $7,346(+118.1 \%)$ \\
Chapparal & 11,018 & $9,270(-15.9 \%)$ & $7,070(-35.8 \%)$ \\
Subtropical Forest & 21,936 & $16,935(-22.8 \%)$ & $13,471(-38.6 \%)$ \\
Tropical Desert & 16,705 & $21,518(+28.8 \%)$ & $26,027(+55.8 \%)$ \\
Tropical Dry Forest & 15,036 & $19,213(+27.8 \%)$ & $27,659(+84.0 \%)$ \\
Tropical Forest & 10,588 & $11,414(+7.8 \%)$ & $11,438(+8.0 \%)$ \\
\hline
\end{tabular}


Supplementary Table 2. Food crop production $\left(10^{12} \mathrm{kcal}\right)$ divided into resilience and Holdridge change quantiles under high emission scenario (SSP1-2.6). See map in Fig. 3.

\begin{tabular}{lrcrr}
\hline Resilience quantiles & $\begin{array}{c}\text { Holdridge change } \\
25-50 \%\end{array}$ & $\begin{array}{r}50-75 \% \\
{[\text { high] }}\end{array}$ & $\begin{array}{r}75-100 \% \\
{[\text { Very high] }}\end{array}$ \\
\hline $75-100 \%$ [very high] & $0.6(0.006 \%)$ & $34(0.3 \%)$ & $562(5.5 \%)$ & $143(1.4 \%)$ \\
$50-75 \%$ [high] & $121(1.2 \%)$ & $167(1.6 \%)$ & $1363(13 \%)$ & $213(2.1 \%)$ \\
$25-50 \%$ [moderate] & $499(4.9 \%)$ & $401(3.9 \%)$ & $827(8.1 \%)$ & $373(3.7 \%)$ \\
$0-25 \%$ [low] & $1756(17 \%)$ & $1746(17 \%)$ & $1925(19 \%)$ & $62(0.6 \%)$ \\
\hline
\end{tabular}

Supplementary Table 3. Food crop production $\left(10^{12} \mathrm{kcal}\right)$ divided into resilience and Holdridge change quantiles under high emission scenario (SSP5-8.5). See map in Fig. 3. Note: Holdridge change quantiles are derived from the SSP1-2.6 scenario.

\begin{tabular}{|c|c|c|c|c|}
\hline \multirow[b]{2}{*}{ Resilience quantiles } & \multicolumn{4}{|c|}{ Holdridge change } \\
\hline & $\begin{array}{r}0-25 \% \\
\text { [low] }\end{array}$ & $\begin{array}{c}25-50 \% \\
\text { [moderate] }\end{array}$ & $\begin{array}{r}50-75 \% \\
\text { [high] } \\
\end{array}$ & $\begin{array}{r}75-100 \% \\
\text { [very high] }\end{array}$ \\
\hline 75-100\% [very high] & $0.02(0.0002 \%)$ & $0.004(0.00004 \%)$ & $1(0.008 \%)$ & $739(7.3 \%)$ \\
\hline $50-75 \%[h i g h]$ & $0.3(0.003 \%)$ & $0.03(0.0003 \%)$ & $101(1.0 \%)$ & $1763(17 \%)$ \\
\hline $25-50 \%$ [moderate] & $4(0.04 \%)$ & $0.4(0.004 \%)$ & $446(4.4 \%)$ & $1650(16 \%)$ \\
\hline $0-25 \%[l o w]$ & $48(0.5 \%)$ & $2(0.02 \%)$ & $2167(21 \%)$ & $3272(32 \%)$ \\
\hline
\end{tabular}

Supplementary Table 4. Livestock production $\left(10^{6} \mathrm{AU}\right)$ divided into resilience and Holdridge change quantiles under high emission scenario (SSP1-2.6). See map in Fig. 3. AU refers to Animal Units (Methods).

\begin{tabular}{lccrc}
\hline Resilience quantiles & $\begin{array}{c}0-25 \% \\
{[\text { low] }}\end{array}$ & $\begin{array}{c}\text { Holdridge change } \\
\text { [moderate] }\end{array}$ & $\begin{array}{r}50-75 \% \\
\text { [high] }\end{array}$ & $\begin{array}{c}75-100 \% \\
\text { [very high] }\end{array}$ \\
\hline $75-100 \%$ [very high] & $3.8(0.2 \%)$ & $22(0.9 \%)$ & $79(3.3 \%)$ & $25(1.1 \%)$ \\
$50-75 \%$ [high] & $60(2.5 \%)$ & $126(5.3 \%)$ & $184(7.8 \%)$ & $47(2.0 \%)$ \\
$25-50 \%$ [moderate] & $138(5.9 \%)$ & $194(8.3 \%)$ & $150(6.4 \%)$ & $59(2.5 \%)$ \\
$0-25 \%$ [low] & $335(14 \%)$ & $538(23 \%)$ & $359(15 \%)$ & $31(1.3 \%)$ \\
\hline
\end{tabular}

Supplementary Table 5. Livestock production $\left(10^{6} \mathrm{AU}\right)$ divided into resilience and Holdridge change quantiles under high emission scenario (SSP5-8.5). See map in Fig. 3. Note: Holdridge change quantiles are derived from the SSP1-2.6 scenario. AU refers to Animal Units (Methods).

\begin{tabular}{|c|c|c|c|c|}
\hline \multirow[b]{2}{*}{ Resilience quantiles } & \multicolumn{4}{|c|}{ Holdridge change } \\
\hline & $\begin{array}{r}0-25 \% \\
{[\text { low] }} \\
\end{array}$ & $\begin{array}{c}25-50 \% \\
\text { [moderate] }\end{array}$ & $\begin{array}{r}50-75 \% \\
\text { [high] } \\
\end{array}$ & $\begin{array}{r}75-100 \% \\
\text { [very high] }\end{array}$ \\
\hline 75-100\% [very high] & $0.1(0.005 \%)$ & $0.05(0.002 \%)$ & $6.8(0.3 \%)$ & $123(5.2 \%)$ \\
\hline $50-75 \%[$ high $]$ & $0.4(0.01 \%)$ & $0.08(0.003 \%)$ & $45(1.9 \%)$ & $370(16 \%)$ \\
\hline $25-50 \%$ [moderate] & $5.8(0.2 \%)$ & $0.2(0.01 \%)$ & $104(4.4 \%)$ & $431(18 \%)$ \\
\hline $0-25 \%[l o w]$ & $6.0(0.3 \%)$ & $0.3(0.01 \%)$ & $447(19 \%)$ & $810(34 \%)$ \\
\hline
\end{tabular}


Supplementary Table 6. Sensitivity analysis to the impact of change in low resilience threshold on_\% of production falling to high change in Holdridge zone and low resilience class.

\begin{tabular}{lrrr}
\hline & \multicolumn{3}{c}{$\begin{array}{l}\text { \% of production falling to } \\
\text { high change in Holdridge } \\
\text { zone and low resilience } \\
\text { class }\end{array}$} \\
\cline { 2 - 4 } & Low resilience threshold & SSP1-2.6 & SSP5-8.5 \\
\hline Food crop production & $20 \%$ & $0.3 \%$ & $27.5 \%$ \\
& $25 \%$ & $0.6 \%$ & $32.1 \%$ \\
\hline Livestock production & $30 \%$ & $1.2 \%$ & $35.8 \%$ \\
\hline & $20 \%$ & $1.0 \%$ & $29.7 \%$ \\
& $25 \%$ & $1.3 \%$ & $34.5 \%$ \\
& $30 \%$ & $1.8 \%$ & $38.9 \%$ \\
\hline
\end{tabular}

Supplementary Table 7. Percentage of population and food production that would fall within and outside 'Safe Climatic Space' (SCS), i.e., climatic conditions where the majority (95\%) of population or food production exist within baseline conditions. Low resilience refers to the bottom $25^{\text {th }}$ percentile of resilience (see Supplementary Fig. $5 d$ ). Results are presented separately for high emission scenario (SSP1-2.6) (a,b) and high emission scenario (SSP5-8.5) (c, d). The likelihood categories of population and food crop production falling outside SCS were determined based on the amount of Global Circulation Models (GCMs) (8 in total) showing that the SCS is left: 0 (very likely inside), 1-3 (likely inside), 4-6 (potentially outside), 7-8 (likely outside).

\begin{tabular}{|c|c|c|c|c|c|}
\hline \multirow[b]{2}{*}{$\begin{array}{l}\text { Food crop production } \\
\text { SSP1-2.6 }\end{array}$} & \multirow{2}{*}{$\begin{array}{r}\text { Ensemble median } \\
\text { Outside SCS }\end{array}$} & \multicolumn{4}{|c|}{ Results based on 8 Global Circulation Models } \\
\hline & & $\begin{array}{l}\text { Very likely } \\
\text { inside }\end{array}$ & Likely inside & Potentially outside & Likely outside \\
\hline Moderate to high resilience & $1.5 \%$ & $42.8 \%$ & $2.0 \%$ & $1.2 \%$ & $0.4 \%$ \\
\hline Low resilience & $6.0 \%$ & $42.5 \%$ & $4.6 \%$ & $4.7 \%$ & $1.7 \%$ \\
\hline Total & $7.6 \%$ & $85.3 \%$ & $6.7 \%$ & $5.9 \%$ & $2.2 \%$ \\
\hline
\end{tabular}

\section{Food crop production} SSP5-8.5

\begin{tabular}{lr|llrr}
\hline Moderate to high resilience & $6.4 \%$ & $35.1 \%$ & $4.5 \%$ & $2.9 \%$ & $4.1 \%$ \\
Low resilience & $24.8 \%$ & $22.1 \%$ & $5.2 \%$ & $6.6 \%$ & $19.6 \%$ \\
Total & $\mathbf{3 1 . 1 \%}$ & $\mathbf{5 7 . 2 \%}$ & $\mathbf{9 . 7 \%}$ & $\mathbf{9 . 5 \%}$ & $\mathbf{2 3 . 6 \%}$ \\
\hline
\end{tabular}

Livestock production SSP1-2.6

\begin{tabular}{ll|llll}
\hline Moderate to high resilience & $1.4 \%$ & $42.0 \%$ & $2.2 \%$ & $1.0 \%$ & $0.5 \%$ \\
Low resilience & $3.2 \%$ & $46.6 \%$ & $4.3 \%$ & $2.2 \%$ & $1.1 \%$ \\
Total & $\mathbf{4 . 6 \%}$ & $\mathbf{8 8 . 6} \%$ & $\mathbf{6 . 5} \%$ & $\mathbf{3 . 2} \%$ & $\mathbf{1 . 7 \%}$ \\
\hline
\end{tabular}

Livestock production

SSP 5-8.5

\begin{tabular}{|c|c|c|c|c|c|}
\hline Moderate to high resilience & $10.1 \%$ & $31.5 \%$ & $3.4 \%$ & $3.3 \%$ & $7.6 \%$ \\
\hline Low resilience & $23.7 \%$ & $21.7 \%$ & $7.0 \%$ & $7.3 \%$ & $18.3 \%$ \\
\hline Total & $33.8 \%$ & $53.2 \%$ & $10.4 \%$ & $10.6 \%$ & $25.8 \%$ \\
\hline
\end{tabular}




\section{References}

1. Fick, S.E., and Hijmans, R.J. (2017). WorldClim 2: new 1-km spatial resolution climate surfaces for global land areas. International Journal of Climatology 37, 4302-4315.

2. Trabucco, A., and Zomer, R. (2019). Global Aridity Index and Potential Evapotranspiration (ET0) Climate Database v2. figshare. Fileset. https://doi.org/10.6084/m9.figshare.7504448.v3.

3. NTSG (2020). MODIS Global Evapotranspiration Project (MOD16) (University of Montana, Numerical Terradynamic Simulation Group (NTSG)).

4. Yu, Q., You, L., Wood-Sichra, U., Ru, Y., Joglekar, A.K.B., Fritz, S., Xiong, W., Lu, M., Wu, W., and Yang, P. (2020). A cultivated planet in 2010 - Part 2: The global gridded agriculturalproduction maps. Earth System Science Data 12, 3545-3572.

5. Gilbert, M., Nicolas, G., Cinardi, G., Van Boeckel, T.P., Vanwambeke, S.O., Wint, G.R.W., and Robinson, T.P. (2018). Global distribution data for cattle, buffaloes, horses, sheep, goats, pigs, chickens and ducks in 2010. Scientific Data 5, 180227.

6. Varis, O., Taka, M., and Kummu, M. (2019). The Planet's Stressed River Basins: Too Much Pressure or Too Little Adaptive Capacity? Earth's Future 7, 1118-1135. 